\title{
Brain Oxygen Tension, Oxygen Supply, and Oxygen Consumption During Arterial Hyperoxia in a Model of Progressive Cerebral Ischemia
}

\author{
SANDRA ROSSI, ${ }^{1}$ NINO STOCCHETTI, ${ }^{1}$ LUCA LONGHI, ${ }^{1}$ MARCELLA BALESTRERI, ${ }^{3}$ \\ DIEGO SPAGNOLI, ${ }^{2}$ ELISA RONCATI ZANIER, ${ }^{1}$ and GUIDO BELLINZONA ${ }^{3}$
}

\begin{abstract}
We investigated the changes in brain oxygen tension $\left(\mathrm{ptiO}_{2}\right)$ after ventilation with pure $\mathrm{O}_{2}$ in order to (1) clarify the pathophysiology of $\mathrm{O}_{2}$ exchange in the cerebral microcirculation; and (2) investigate the relationship between brain $\mathrm{O}_{2}$ tension, $\mathrm{O}_{2}$ delivery, and consumption in steady-state conditions during stepwise cerebral blood flow (CBF) reductions. A swine model was developed to reduce CBF in three stable steps: (1) baseline (CBF 100\%), (2) CBF of 50-60\% of baseline, and (3) CBF of $<30 \%$ of baseline. CBF was reduced by infusing saline into the left lateral ventricle through a catheter connected with an infusion pump. At each step, hyperoxia was tested by increasing the inspired oxygen fraction up to $100 \%, \mathrm{PtiO}_{2}$ reflected the $\mathrm{CBF}$ reductions, since it was respectively $27.95( \pm 10.15), 14.77( \pm 3.58)$, and $3.45( \pm 2.89) \mathrm{mm}$ Hg during the three CBF steps. Hyperoxia was followed by an increase in ptiO $_{2}$, although the increase was significantly lower when hyperoxia was applied during progressive ischemia. $\mathrm{O}_{2}$ supply to the brain did not change during hyperoxia. Arteriovenous oxygen difference $\left(\mathrm{AVDO}_{2}\right)$ decreased during the phases of intact $\mathrm{CBF}$ and moderate impairment, but not during the phase of severe $\mathrm{CBF}$ reduction. In conclusion, ptiO $_{2}$ reductions closely reflect the imbalance between oxygen delivery and demand; this implies a link between low ptiO $_{2}$ and defective $\mathrm{O}_{2}$ supply due to impaired CBF. However, this relation is not necessarily reciprocal, since manipulating brain oxygen tension does not always influence brain oxygen delivery, as in the case of ventilation with pure oxygen.
\end{abstract}

Key words: $\mathrm{AVDO}_{2}$; brain oxygenation; cerebral ischemia; hyperoxia; $\mathrm{ptiO}_{2}$

\section{INTRODUCTION}

I SCHEMIA has been identified as a pathway of cerebral damage after head injury (Graham et al., 1978; Bouma et al., 1991). Therefore, one of the major aims of research into severe head injury is to achieve a better under- standing of how brain metabolism is affected and to assess the adequacy of the transport of oxygen and other energy substrates to the brain parenchyma. This is based on the concept that ensuring cerebral oxygenation and an adequate supply of metabolites is the basis for maintaining the viability and function of the damaged CNS.

${ }^{1}$ Department of Anesthesia and Intensive Care and ${ }^{2}$ Institute of Neurosurgery, Ospedale Maggiore Policlinico IRCCS, Milano, and ${ }^{3}$ Department of Anesthesia and Intensive Care and Experimental Surgery, Policlinico S. Matteo, IRCCS, Pavia, Italy. 
Global monitoring provides an indirect estimate of the adequacy of substrate supply to the brain. Brain oxygen tension $\left(\mathrm{ptiO}_{2}\right)$ can be measured locally using a Clark electrode implanted in the cerebral parenchyma. The method has been validated for use in humans and has been confirmed as a reliable and stable indicator of local oxygenation (Dings et al., 1997, 1998). $\mathrm{PtiO}_{2}$ monitoring is useful to assess the efficacy of treatments based on their ability to restore adequate $\mathrm{ptiO}_{2}$ levels (Kiening et al., 1997; Zauner et al, 1997; Stocchetti et al., 1998).

Interest has been renewed on the effect of arterial hyperoxia, obtained by ventilation with pure oxygen, on brain oxygenation. The $\mathrm{ptiO}_{2}$ response to hyperoxia varies widely in different patients; it may also vary considerably during the clinical course in head injury (Van Santbrink et al., 1996). However, the pathophysiology of the oxygen reactivity and the meaning of its variability are not clearly understood. Arterial hyperoxia has been used in order to elucidate its effect on cerebral blood flow (CBF), cerebral metabolism, and their coupling. This procedure markedly increases $\mathrm{ptiO}_{2}$ and may also enhance $\mathrm{O}_{2}$ delivery to the neurons (Menzel et al., 1999).

Our group developed a swine model of stepwise reduction of $\mathrm{CBF}$, structured to achieve three steps of stable CBF: the first is intact $\mathrm{CBF}$, the second a mild CBF reduction, and the third a severe $\mathrm{CBF}$ impairment. The model can be used to explore the interactions between $\mathrm{ptiO}_{2}$, oxygen delivery and consumption, and blood flow in stable conditions.

The present experiment was designed to investigate the effects of arterial hyperoxia obtained by ventilation with pure oxygen on cerebral oxygenation. Specifically, we sought to gain further insight into the pathophysiology of oxygen exchange in brain tissue during mild and severe CBF impairment while also assessing how changes in brain oxygen tension are related to brain oxygen delivery and consumption when hyperoxia is applied during intact, moderately reduced, or severely impaired CBF.

\section{MATERIALS AND METHODS}

The experiments were conducted in accordance with the guidelines for animal research published by the European Union and acknowledged by Italian Law no. 116/92.

Seven 8-week-old domestic pigs, weighing 18-22 kg, were used. They had free access to food and water until the night before the experiment. Thirty minutes before the induction of anesthesia they were given an intramuscular bolus of $100 \mathrm{mg}$ of ketamine. This ensured adequate sedation before general anesthesia, which was induced with propofol $(2 \mathrm{mg} / \mathrm{kg})$ and succinylcholine (1 $\mathrm{mg} / \mathrm{kg}$ ) and maintained with isoflurane $1.0 \%$; myorelax- ation during the experiment was maintained by 0.3 $\mathrm{mg} / \mathrm{kg} / \mathrm{h}$ pancuronium bromide. An orotracheal tube was positioned, and ventilation was administered with a controlled volume modality to achieve $\mathrm{paCO}_{2} 30-35 \mathrm{~mm} \mathrm{Hg}$. Inspiratory oxygen fraction $\left(\mathrm{FiO}_{2}\right)$ was kept at $25 \%$ and $30 \%$ to obtain a $\mathrm{paO}_{2}$ of $100-120 \mathrm{~mm} \mathrm{Hg}$.

\section{Placement of the Probes and Monitoring}

Deep branches of the carotid artery and the jugular vein were surgically exposed and cannulated for monitoring arterial pressure, arterial blood gases, arterial hemoglobin oxygen saturation $\left(\mathrm{SaO}_{2}\right)$, and infusion of fluids. Saline was infused at the rate of $3 \mathrm{~mL} / \mathrm{kg} / \mathrm{h}$. Rectal temperature was monitored and kept at $37.5-38.5^{\circ} \mathrm{C}$ using heating pads. The animals were placed in the prone position and a linear incision was made along the midline from the inion to the nasion. The scalp was exposed, and three burr holes were placed $1.5 \mathrm{~cm}$ from the midline on the right side through and across the coronal suture. Two more burr holes were made: one through the sagittal suture and the other through the left coronal suture $(1.5 \mathrm{~cm}$ from the midline). Through a dural incision in the cerebral parenchyma (from the front to the rear and on the right side), we placed the tips of the CBF probe, the $\mathrm{ptiO}_{2}$ probe, and the intracranial pressure (ICP) transducer. Through the burr hole on the left, a ventricular catheter was placed and connected to an infusion pump. The burr hole through the sagittal suture gave access to the superior sagittal sinus and was punctured for monitoring venous blood gases and venous hemoglobin oxygen saturation $\left(\mathrm{SsO}_{2}\right)$. The position of the probes on the skull is illustrated in Figure 1.

ICP was measured by a parenchymal fiberoptic device (Camino Lab). $\mathrm{PtiO}_{2}$ was measured by a polarographic Clark-type microcatheter (Licox, GMS). $\mathrm{PtiO}_{2}$ was allowed to stabilize for $2 \mathrm{~h}$ after insertion of the catheter and was corrected for rectal temperature during the experiment. After the $\mathrm{ptiO}_{2}$ probe was removed, we checked the sensitivity drift, as suggested by the manufacturer. CBF was obtained continuously by laser Doppler flowmetry (Peri-flux, Perimed) and was calculated as the change in signal, as a percentage of the baseline.

Intermittent samples were drawn simultaneously from superior sagittal sinus and from the artery in order to calculate the arteriovenous oxygen difference $\left(\mathrm{AVDO}_{2}\right)$, as follows:

$$
\mathrm{Hb} * 1.34 *\left(\mathrm{SaO}_{2} \%-\mathrm{SsO}_{2} \%\right)+0.003\left(\mathrm{paO}_{2}-\mathrm{psO}_{2}\right)
$$

Oxygen delivery to the brain $\left(\mathrm{DO}_{2}\right)$ was calculated by multiplying arterial oxygen content by estimated CBF, assuming that the intact CBF amounted to $50 \mathrm{~mL} / 100 \mathrm{~g} / \mathrm{min}$. Cerebral electrical activity was monitored by a three-point 


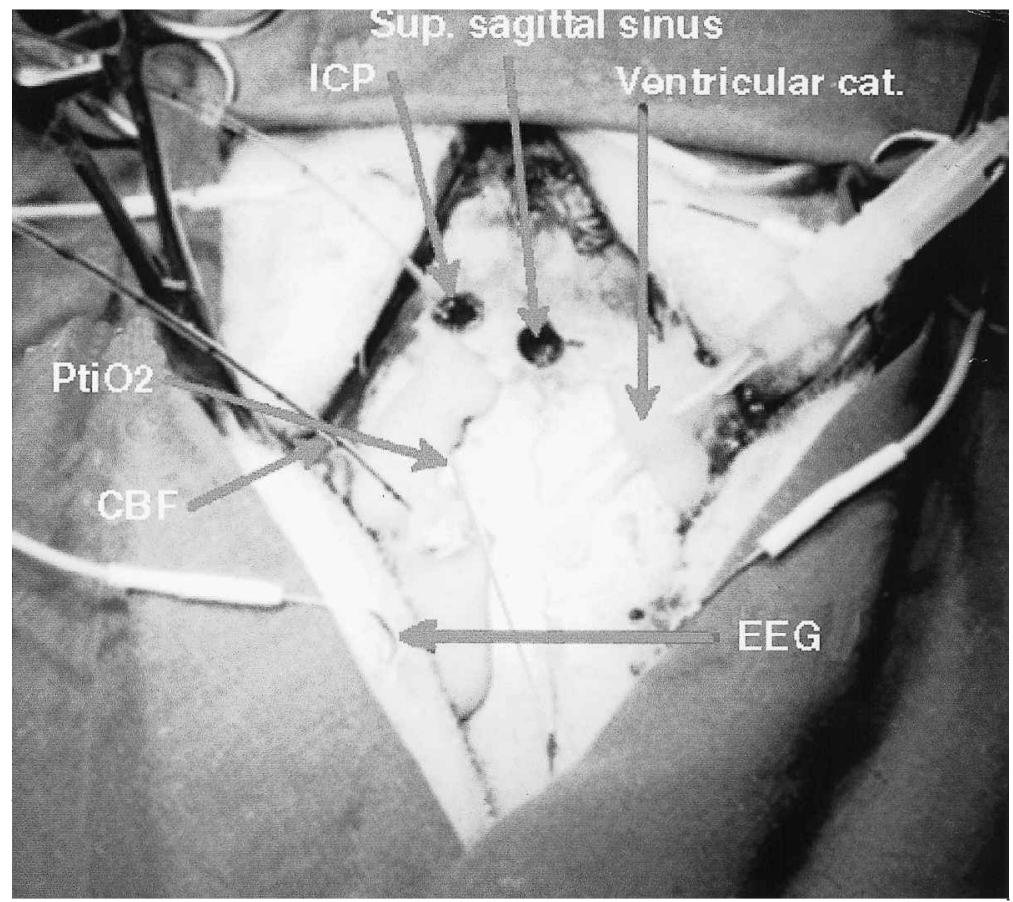

FIG. 1. Probes and catheters position on the skull.

EEG (Cerebro-trac, SDR Medical). Mean arterial pressure (MAP), ICP, cerebral perfusion pressure (CPP), $\mathrm{PtiO}_{2}$, end-tidal $\mathrm{CO}_{2}, \mathrm{CBF}$, and temperature signals were filtered by an analog digital converter (Mac Lab), and stored in a Macintosh computer for offline analysis.

\section{Induction of Progressive Ischemia}

The model was developed to achieve progressive CBF reduction in three stable steps: baseline (CBF 100\%), CBF $50-60 \%$ of baseline, and $20-30 \%$ of baseline. CBF was reduced by inducing intracranial hypertension by infusing saline (warmed to $38^{\circ} \mathrm{C}$ ) into the left lateral ventricle through a catheter connected with an infusion pump. ICP was raised stepwise by boluses of saline. Once the end point was reached (in terms of reduction of CPP and $\mathrm{CBF}$ ), the velocity of fluid infusion into the ventricles was titrated to keep ICP, CPP, and CBF stable during each step. Cushing response elicited by the ICP increase was inhibited by the infusion of $\alpha-\beta$ blockers (repeated bolus of labetalol $0.5-1 \mathrm{mg} / \mathrm{kg}$ ).

At the end of the experiment, the animals were euthanized by increasing the isoflurane concentration to $4 \%$ and by infusing $60 \mathrm{mEq}$ of $\mathrm{KCl}$.

\section{Hyperoxia Test}

During each stage of the experiment (CBF 100\%, $50-60 \%$, and $20-30 \%$ of baseline), a hyperoxia test was done. Once ICP, CPP, CBF, and $\mathrm{ptiO}_{2}$ were stable, the inspired oxygen fraction was raised from $25-30 \%$ to $100 \%$. Ventilation with pure oxygen was continued until ptiO $\mathrm{P}_{2}$ and the other intracranial parameters plateaued. At the end of the test, $\mathrm{FiO}_{2}$ was brought back to the starting value.

\section{Statistics}

Data were summarized as mean $\pm \mathrm{SD}$. Intracranial and extracranial parameters at the three different $\mathrm{CBF}$ values were compared using repeated-measures analysis of variance. A paired $t$ test was used to compare differences between two groups. A $p<0.05$ was considered as statistically significant.

\section{RESULTS}

\section{Description of the Model}

Intracranial and stystemic variables. The course of intracranial variables is shown in Figure 2. CPP and CBF reduction reflected both the increase in ICP and the slight reduction of MAP as a consequence of the use of $\alpha, \beta$ blockers to blunt the Cushing reflex. The end points in terms of reduction in CPP and thus in CBF were reached stepwise. The two parameters were stable during the three stages, which lasted (1) 49.8 ( \pm 10.49$)$, (2) 55.7 ( \pm 19.8 ), 

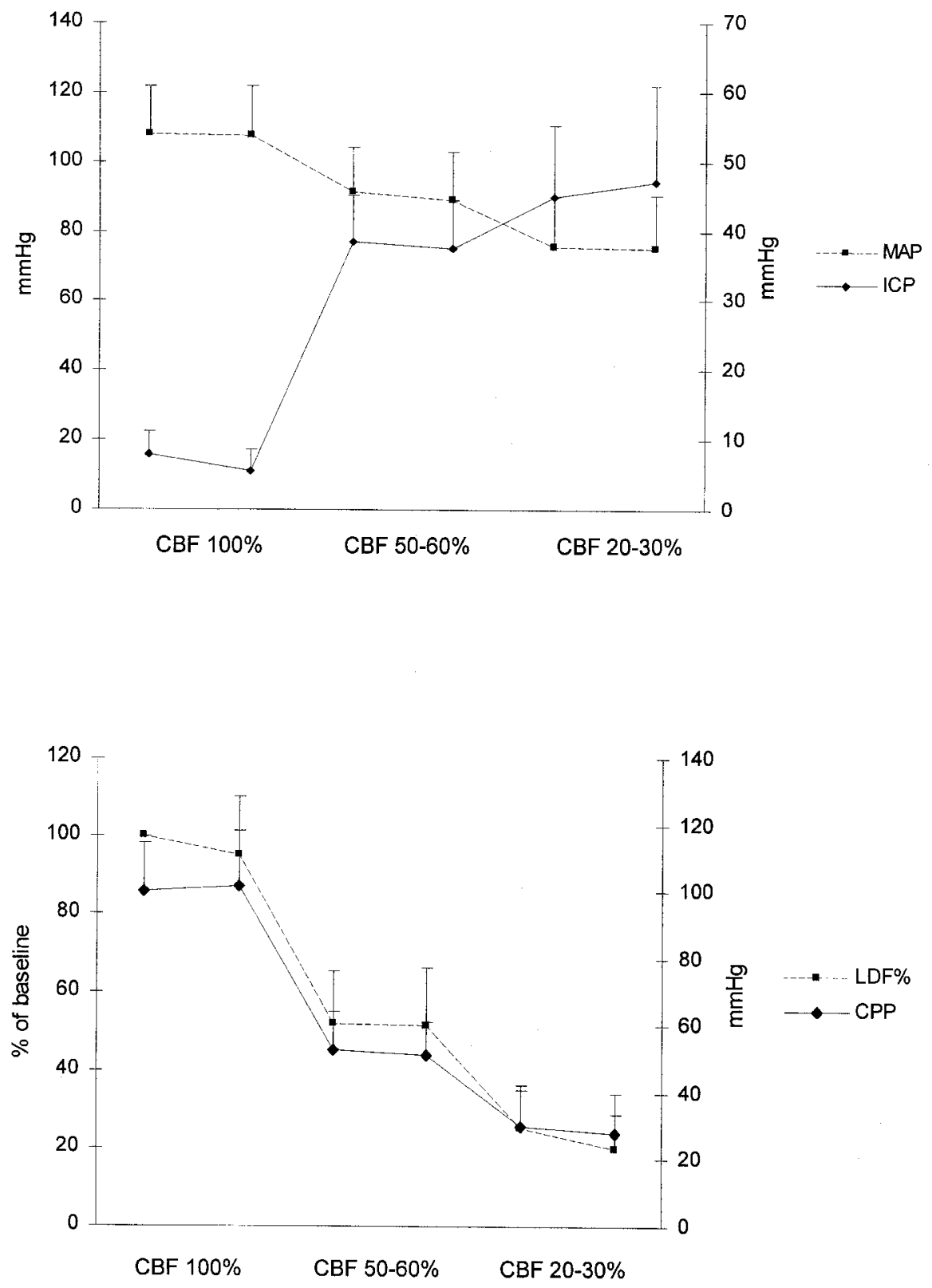

FIG. 2. (Upper panel) Intracranial pressure (ICP) and mean arterial blood pressure (MAP) during the three steps of the experiment. (Lower panel) Cerebral perfusion pressure (CPP) and cerebral blood flow measured by laser Doppler flowmetry $(\mathrm{LDF} \%) . \mathrm{CBF}$ was estimated by calculating the change of the signal as a percentage of baseline. $\mathrm{Bar}=\mathrm{SD}$.

and (3) $48.28( \pm 11.32)$ min. CBF reduction was accompanied by a parallel decrease in $\mathrm{O}_{2}$ delivery and by a significant increase in $\mathrm{AVDO}_{2}$, consistent with impending ischemia (Figure 3). The venoarterial difference of $\mathrm{paCO}_{2}\left(\mathrm{VACO}_{2}\right)$ confirmed these findings, significantly increasing from $10( \pm 4) \mathrm{mm} \mathrm{Hg}$ at the baseline, to 14.5 $( \pm 4.11)$ and to $31.2( \pm 9.0) \mathrm{mm} \mathrm{Hg}$ in the two subsequent stages $(p<0.01)$. At the baseline and in the two phases of CBF reduction, blood gases and internal tem- perature remained constant; there was a small drop in hemoglobin concentration, probably due to frequent blood sampling (Table 1).

Electroencephalographic findings. Progressive CBF impairment was accompanied by a sustained reduction in EEG amplitude during the first phase (CBF 50-60\% of baseline) and by electrical silence during the second (CBF $20-30 \%$ of baseline; Figure 4). 


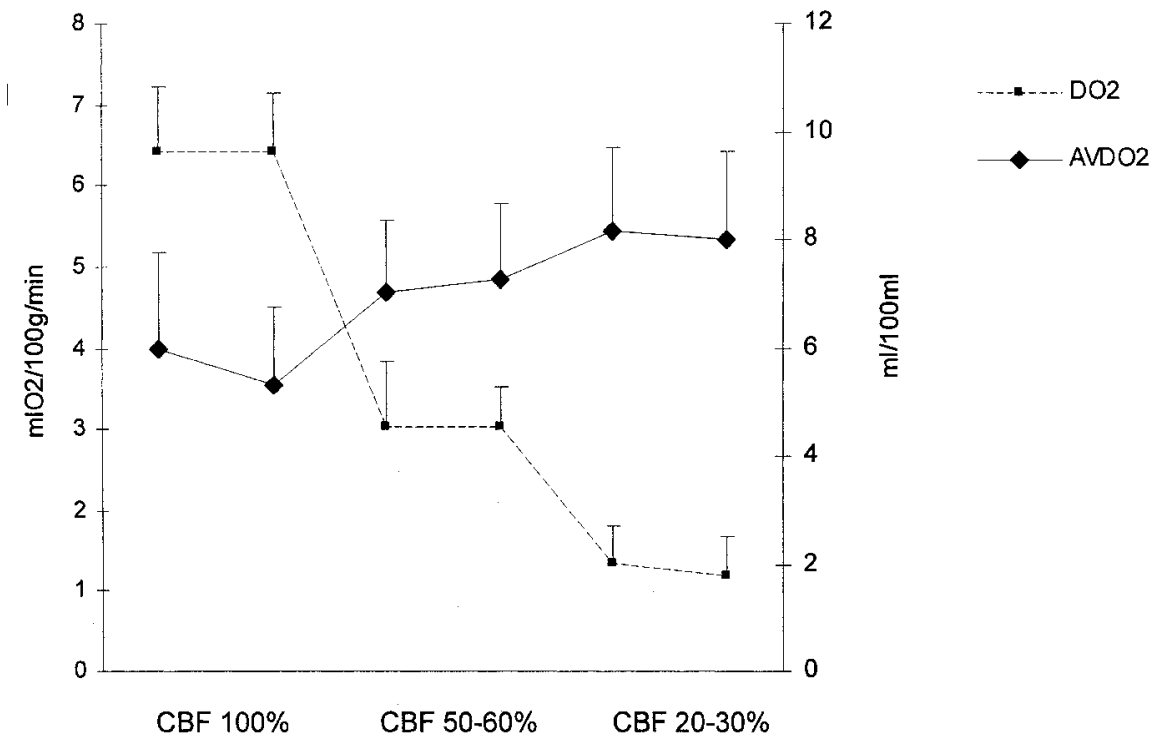

FIG. 3. Arteriovenous oxygen difference $\left(\mathrm{AVDO}_{2}\right)$ and brain oxygen delivery $\left(\mathrm{DO}_{2}\right)$. The latter was calculated by multiplying arterial oxygen content by estimated CBF, assuming the intact $\mathrm{CBF}$ as $50 \mathrm{~mL} / 100 \mathrm{~g} / \mathrm{min}(p<0.05)$.

$\mathrm{PtiO}_{2}$ response to ischemia. In seven experiments, eight $\mathrm{ptiO}_{2}$ catheters were used. One needed to be replaced because of malfunction, probably due to careless storage. The others provided reliable readings throughout the experiment, as confirmed by the final drift check. In all cases the probe was allowed to stabilize for $2 \mathrm{~h}$ after insertion. $\mathrm{PtiO}_{2}$ reflected CBF reductions, since it was $27.95( \pm 10.15) \mathrm{mm} \mathrm{Hg}$ with intact CBF. It declined to $14.77( \pm 3.58) \mathrm{mm} \mathrm{Hg}$ during the first $\mathrm{CBF}$ reduction, dropped to $3.45( \pm 2.89) \mathrm{mm} \mathrm{Hg}$ during the second reduction, and finally fell to $0 \mathrm{~mm} \mathrm{Hg}$ when CBF was completely abolished.

\section{Response to Hyperoxia}

$\mathrm{PtiO}_{2}$ response. Intracranial and extracranial parameters that might have influenced the response to hyperoxia remained stable during the maneuvers (Table 2). $\mathrm{PaO}_{2}$ increments caused by ventilation with pure oxygen were not different during the three phases of the experiment. Arterial hyperoxia was followed by a $\mathrm{ptiO}_{2}$ increase ex- cept in one case when ptiO $\mathrm{P}_{2}$ dropped close to $0 \mathrm{~mm} \mathrm{Hg}$ after severe $\mathrm{CBF}$ reduction. $\mathrm{PtiO}_{2}$ and $\mathrm{paO}_{2}$ changes during hyperoxia in the three stages of the experiment are presented in Figure 5. The response of $\mathrm{ptiO}_{2}$ followed a wash-in curve with an early phase of rapid increase followed by a flex-point and a plateau. In order to standardize our analysis of the behavior of $\mathrm{ptiO}_{2}$ after arterial hyperoxia, we considered the rise in the first minute after induction of hyperoxia (the phase of the highest response). The increase in $\mathrm{ptiO}_{2}$ was significantly lower when hyperoxia was applied during CBF reduction, and this was confirmed when the values were corrected for $\mathrm{PaO}_{2}$ as indicated by the following calculation:

$$
\left(\mathrm{ptiO}_{21 \text { st minute }}-\mathrm{ptiO}_{2 \text { base }}\right) /\left(\mathrm{paO}_{2100 \%}-\mathrm{paO}_{2 \text { base }}\right) * 100
$$

where $\mathrm{ptiO}_{21 \text { st minute }}$ is the value after the first minute of hyperoxia, $\mathrm{ptiO}_{2 \text { base }}$ is the value before hyperoxia, $\mathrm{paO}_{2100 \%}$ is $\mathrm{O}_{2}$ arterial partial pressure with ventilation with pure $\mathrm{O}_{2}$ and $\mathrm{paO}_{2}$ base is $\mathrm{O}_{2}$ arterial partial pressure before hyperoxia was induced (Figure 6).

Table 1. Blood Gases, Hemoglobin, and Internal Temperature

\begin{tabular}{lcccccc}
\hline & $\mathrm{Hb}(\mathrm{g} / \mathrm{dl})$ & $\mathrm{PaO}_{2}(\mathrm{~mm} \mathrm{Hg})$ & $\mathrm{PaCO}_{2}(\mathrm{~mm} \mathrm{Hg})$ & $\mathrm{SaO}_{2} \%$ & $\mathrm{pH}$ & $\mathrm{T}^{\circ} \mathrm{C}$ \\
\hline $\mathrm{CBF}$ 100\% & $9.0( \pm 1.25)$ & $120( \pm 19.9)$ & $38( \pm 2.58)$ & 100 & $7.40( \pm 0.064)$ & $37.8( \pm 0.30)$ \\
CBF 50-60\% of baseline & $8.3( \pm 1.43)$ & $121( \pm 24.5)$ & $37.1( \pm 3.07)$ & 100 & $7.41( \pm 0.054)$ & $37.5( \pm 0.45)$ \\
CBF 20-30\% of baseline & $7.9( \pm 1.13)$ & $113( \pm 26.9)$ & $37.7( \pm 1.97)$ & 100 & $7.40( \pm 0.044)$ & $37.9(0.29)$ \\
Repeated-measures analysis & $\mathrm{NS}$ & $\mathrm{NS}$ & $\mathrm{NS}$ & $\mathrm{NS}$ & $\mathrm{NS}$ \\
\hline
\end{tabular}

CBF, cerebral blood flow; NS, not significant. 
$\mathrm{DO}_{2}$ and $\mathrm{AVDO}_{2}$. In each of the three steps of the experiment, $\mathrm{CBF}$ showed a slight reduction during hyperoxia and a restoration of the original $\mathrm{CBF}$ at the end of the hyperoxia test, as indicated in Figure 7. To clarify whether the increase of $\mathrm{ptiO}_{2}$ due to hyperoxia reflected an increased oxygen supply, we multiplied the arterial oxygen content by the relative value of the $\mathrm{CBF} . \mathrm{O}_{2}$ supply to the brain did not change during hyperoxia in any of the three steps of the experiment (Figure 8, upper panel). We evaluated the effects of arterial and cerebral hyperoxia on oxygen extraction by comparing $\mathrm{AVDO}_{2}$ during normo- and hyperoxia for the three CBF levels. $\mathrm{AVDO}_{2}$ decreased significantly during hyperoxia when $\mathrm{CBF}$ was normal or mildly reduced; it remained unchanged during severe CBF reduction (Figure 8, lower panel).

\section{DISCUSSION}

Disturbances of oxygen utilization by the brain are a common mechanism of damage after head injury (Bergsneider et al., 1997; Bouma et al., 1991; Cormio et al., 1999; Gopinath et al., 1994). Like in peripheral tissues, this may be due to inadequate $\mathrm{O}_{2}$ uptake, inadequate $\mathrm{O}_{2}$ delivery, or mitochondrial dysfunctions (Pinsky, 1994). These disturbances have been amply reported in the literature and have been associated with unfavorable outcome after head injury. However, a full characterization and description of the pathophysiology of gas exchange and metabolism in the brain is lacking, making it hard to assess the real efficacy of treatments to restore appropriate $\mathrm{O}_{2}$ delivery.

In our experimental model, reduction of $\mathrm{CBF}$ was achieved by injecting volume into the ventricular system, a widely described technique (Maas et al., 1993). The primary aim of the model was to obtain reproducible steps of CBF decline, stable enough to allow the study of $\mathrm{PtiO}_{2}$, oxygen delivery and $\mathrm{AVDO}_{2}$ in response to superimposed perturbations and interventions.

The end points of CPP and CBF reduction were obtained in all the animals studied, with only small variation. The continuous infusion of volume into the system enabled us to maintain the desired CBF reduction and, by administering $\alpha, \beta$ blockers, we were able to limit the Cushing response, which would tend to raise CBF closer to physiological levels by increasing arterial pressure and heart rate through sympathetic activation. It might be argued that the use of labetalol may have caused an impairment of autoregulation which could have affected cerebral oxygenation. Findings on how the adrenergic system affects cerebrovascular tone are often contradictory, so it is difficult to assess the drug's impact on au- toregulation (Go, 1991). Blunting the Cushing response was essential in this experiment in order to obtain the stepwise CBF reduction, and we do not know what would happen to brain oxygen tension without the $\alpha, \beta$ blocker.

$\mathrm{PtiO} 2$ values in case of intact $\mathrm{CBF}$ were around $20 \mathrm{~mm}$ $\mathrm{Hg}$; the value declined parallel to the flow reduction, confirming extensive reports about the $\mathrm{ptiO}_{2}$ threshold for ischemia (Doppenberg et al., 1998; Kiening et al., 1996; Maas et al., 1993; Valadka, 1998).

During these controlled "staircase" CBF reductions, we were able to estimate brain oxygen delivery. However, as we do not know the absolute value of CBF, the measure had to be extrapolated; nevertheless, with the stable conditions and a global reduction of flow, this extrapolation should give a close approximation of the change in oxygen supply to the brain at different levels of $\mathrm{CBF}$. The symmetrical increase of $\mathrm{AVDO}_{2}$ further confirms that there are situations where CBF becomes progressively less able to meet the tissue's metabolic demand. $\mathrm{AVDO}_{2}$, for instance, was $7.01( \pm 1.31) \mathrm{mL} / 100$ $\mathrm{mL}$ during mild reduction of $\mathrm{CBF}$ and $8.16( \pm 1.54)$ $\mathrm{mL} / 100 \mathrm{~mL}$ during marked flow reduction, in agreement with the thresholds for ischemia reported elsewhere (Gibbs et al., 1942; Robertson et al., 1989). Venous-arterial difference in $\mathrm{pCO}_{2}$, which has been recently suggested as an indicator of critical hypoperfusion and ischemia, also increased during the three stages of the experiment (Weil et al., 1986; Zhang and Vincent, 1993).

$\mathrm{PtiO}_{2}$ increased after the induction of arterial hyperoxia, the extent of this rise depending on the initial CBF value: it was close to $6 \mathrm{~mm} \mathrm{Hg} / \mathrm{min}$ when $\mathrm{CBF}$ was intact and fell to $2.6 \mathrm{~mm} \mathrm{Hg} / \mathrm{min}$ when $\mathrm{CBF}$ was severely compromised.

Our data on how $\mathrm{ptiO}_{2}$ reacts to hyperoxia may help clarify the pathophysiology of $\mathrm{ptiO}_{2}$ readings provided by polarographic sensors when progressive ischemia is induced. Tissue oxygenation depends on the balance between microcirculatory $\mathrm{O}_{2}$ delivery and parenchymal $\mathrm{O}_{2}$ demand. The characteristics affecting $\mathrm{O}_{2}$ response are the permeability of the tissue itself to $\mathrm{O}_{2}$ (depending on solubility and the $\mathrm{O}_{2}$ diffusion coefficient) and the spatial distribution and activity of the mitochondria with respect to the source of $\mathrm{O}_{2}$ (namely arterioles and capillaries; Leach and Treacher, 1998; Treacher and Leach, 1998; Lubbers, 1977; Pittman, 1999).

The diffusion gradient between the vessels and the tissue should be higher in case of ischemia, so the $\mathrm{ptiO}_{2}$ response to arterial hyperoxia would be expected to be greater in case of low $\mathrm{CBF}$ and low baseline $\mathrm{ptiO}_{2}$, which was not the case in our experiment. The different response to hyperoxia during ischemia is thus consistent with an increase in the diffusion distance due to a re- 

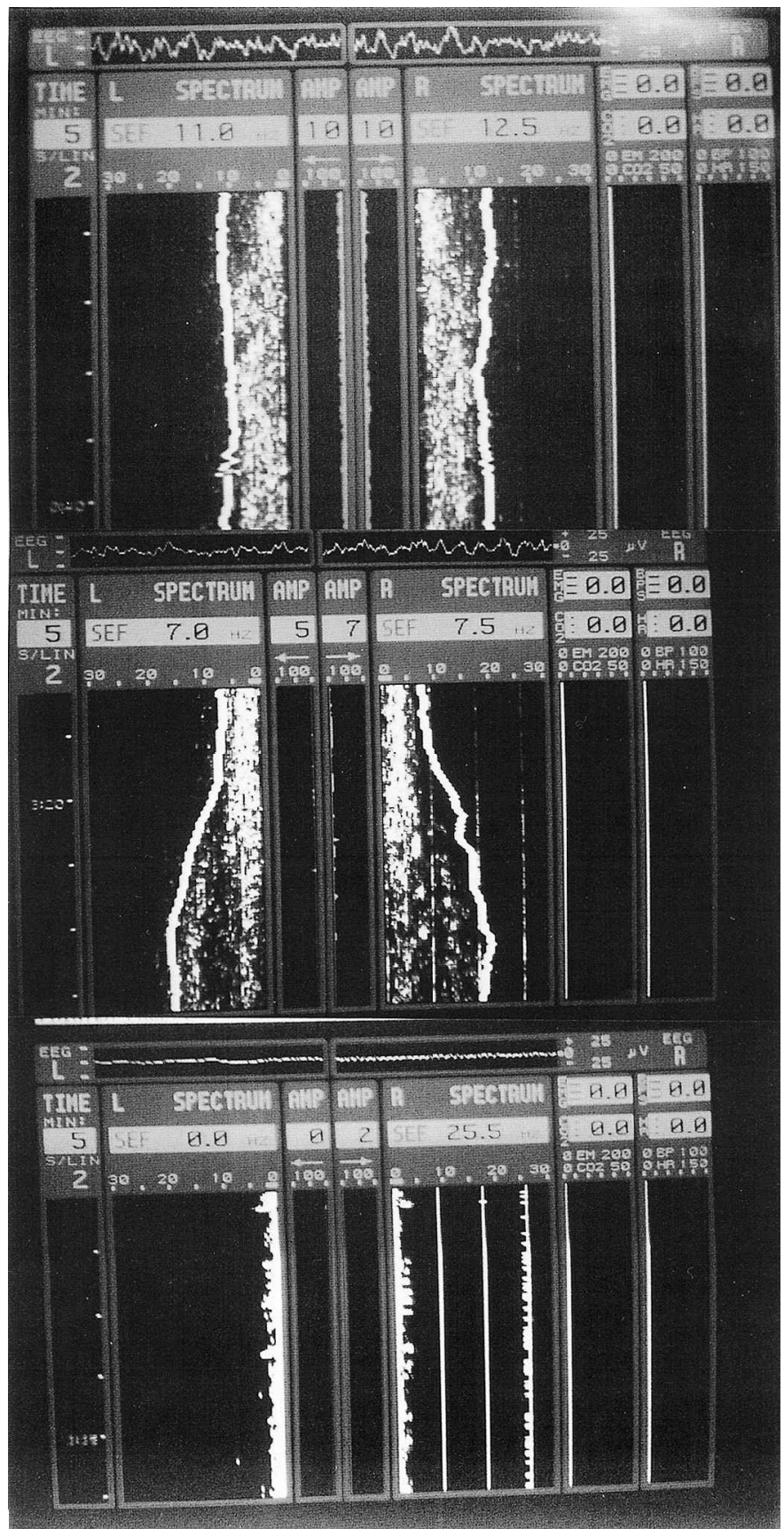

FIG. 4. EEG patterns during the experiment. From the upper to the lower part of the figure, EEG during intact, moderately, and severely reduced CBF. In each image, beside the real-time EEG signal, the average amplitude (AMP) and the highest dominant frequency in the EEG signal (SPECTRUM) are presented.

duction in microvasculature density per unit of tissue. We therefore believe that the importance of the $\mathrm{ptiO}_{2}$ response to hyperoxia provides further evidence that $\mathrm{ptiO}_{2}$ readings by the polarographic sensor are primarily the expression of the spatial distribution and of the density of arterioles and capillaries in the parenchyma. We have confirmed the results of this animal study in patients suffering head injury and subarachnoid hemorrhage, in which the $\mathrm{ptiO}_{2}$ probe was placed in low-flow brain areas (Longhi et al., 1999).

The second issue we set out to address was the relationship between the changes in $\mathrm{ptiO}_{2}$ and oxygen de- 
ROSSI ET AL.

Table 2. Mean Arterial Pressure, Intracranial Pressure, and paCO 2 During Hyperoxia in the Three Stages of the Experiment (No Significant Differences Were Detected)

\begin{tabular}{|c|c|c|c|c|c|c|}
\hline & \multicolumn{2}{|c|}{$M A P(m m ~ H g)$} & \multicolumn{2}{|c|}{$I C P(m m ~ H g)$} & \multicolumn{2}{|c|}{$\mathrm{paCO}_{2}(\mathrm{~mm} \mathrm{Hg})$} \\
\hline & Normoxia & Hyperoxia & Normoxia & Hyperoxia & Normoxia & Hyperoxia \\
\hline $\mathrm{CBF} 100 \%$ & $107.8( \pm 13.8)$ & $110( \pm 14.6)$ & $8( \pm 3.1)$ & $7.3( \pm 4.2)$ & $38.2( \pm 3.2)$ & $36.4( \pm 5.59)$ \\
\hline CBF 50-60\% & $91.42( \pm 12.7)$ & $89.2( \pm 14.6)$ & $38.5( \pm 6.5)$ & $36.4( \pm 6.77)$ & $37.1( \pm 3.07)$ & $37.4( \pm 4.11)$ \\
\hline CBF $20-30 \%$ & $75.28( \pm 14.6)$ & $74.1( \pm 17.7)$ & $45( \pm 10)$ & $45.5( \pm 12.9)$ & $37.7( \pm 1.97)$ & $39.8( \pm 3.5)$ \\
\hline
\end{tabular}

MAP, mean arterial pressure; $\mathrm{ICP}$, intracranial pressure; $\mathrm{CBF}$, cerebral blood flow.

$\mathrm{paO} 2$

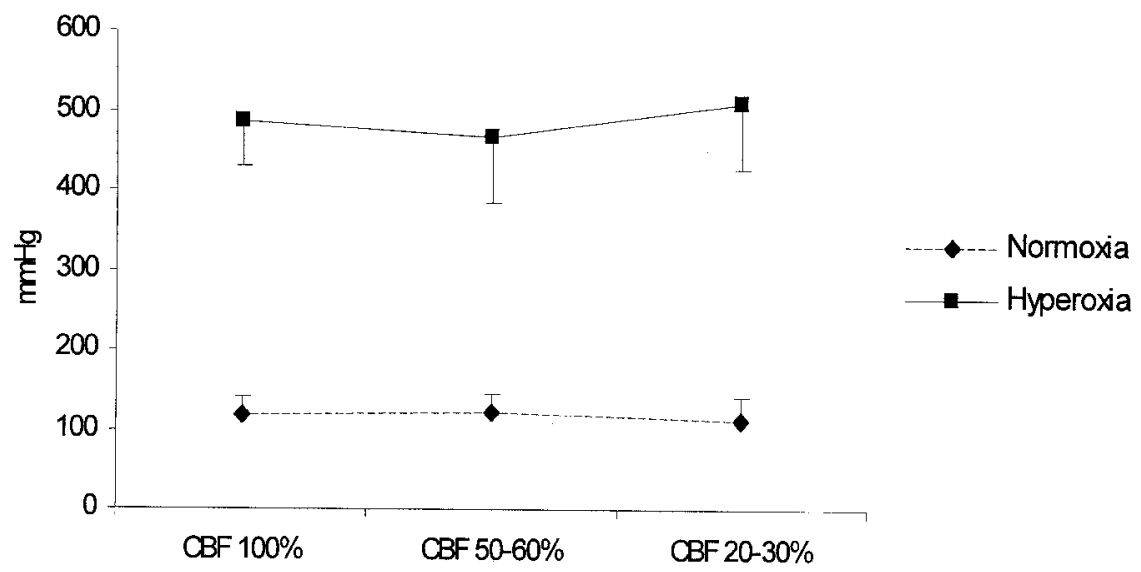

ptiO2

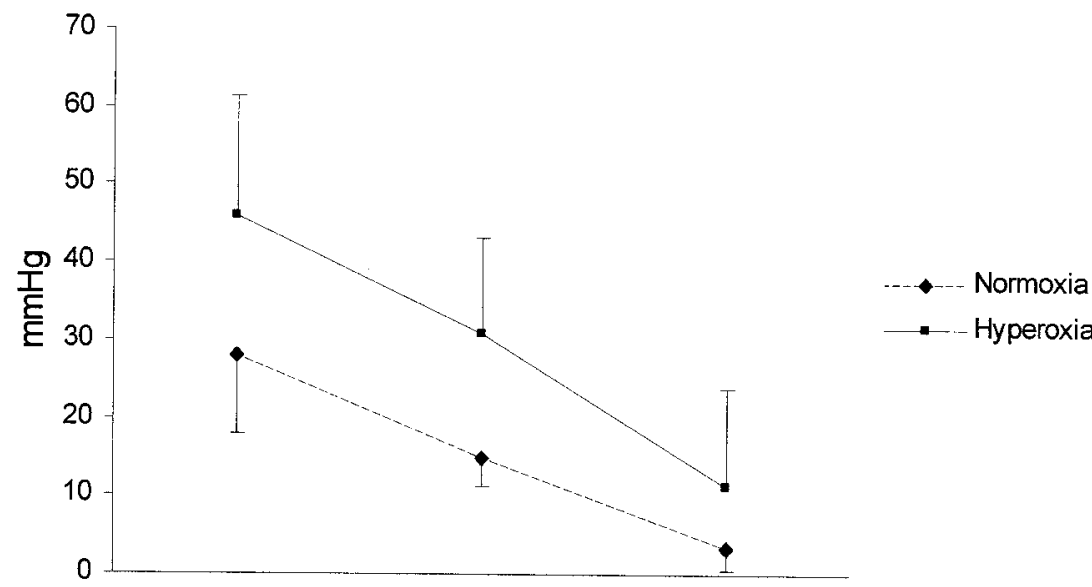

CBF $100 \% \quad$ CBF $50-60 \% \quad$ CBF $20-30 \%$

FIG. 5. Arterial $\mathrm{O}_{2}$ partial pressure $\left(\mathrm{PaO}_{2}\right)$ in the upper panel and brain $\mathrm{O}_{2}$ tension (ptiO $)_{2}$ in the lower panel during ventilation with inspired oxygen fractions of $25-30 \%$ and $100 \%$. 


\section{ARTERIAL HYPEROXIA AND BRAIN OXYGENATION}

口 PtiO2 1st min $=\mathrm{PtiO} 2$ 1st $\mathrm{min} /$ delta $\mathrm{paO} 2$

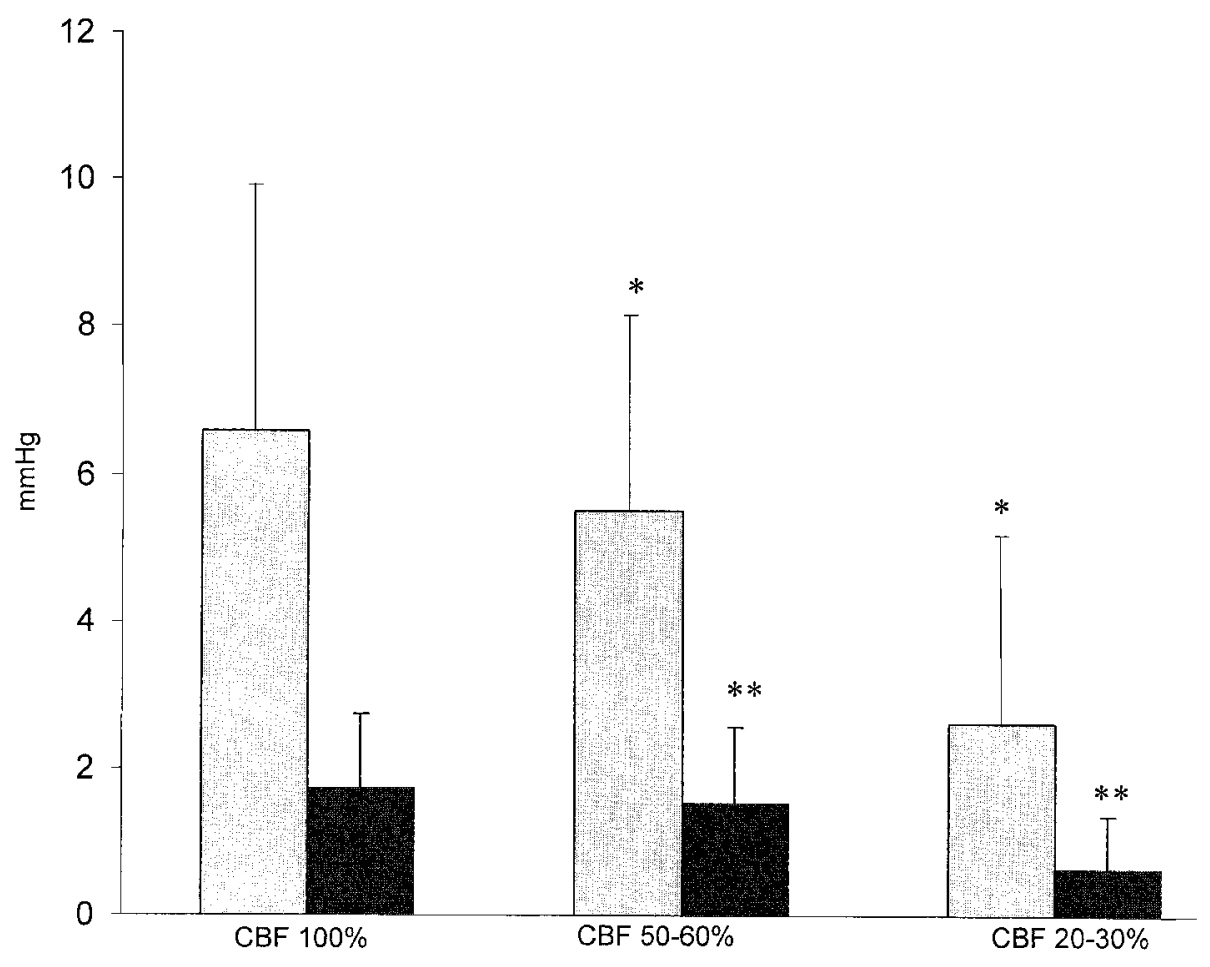

FIG. 6. $\mathrm{PtiO}_{2}$ rising in the first minute after induction of hyperoxia and the same value corrected for the change in $\mathrm{paO}_{2}$ using the calculation reported in the text. ${ }^{*} p<0.05$ by using repeated-measures analysis of variance for $\mathrm{PtiO}_{2}$ rising in the first minute. $* * p<0.05$ for $\mathrm{PtiO}_{2}$ change corrected for $\mathrm{paO}_{2}$.

livery to the brain, in particular whether the increase in brain oxygen tension induced by arterial hyperoxia corresponded to an increase in the volumes of oxygen available for the tissue's metabolic needs. One of the main findings was that in conditions of moderate or deep $\mathrm{CBF}$ reduction, raising $\mathrm{O}_{2}$ brain partial pressure did not necessarily increase oxygen delivery. $\mathrm{O}_{2}$ supply is in fact the product of arterial blood oxygen content and blood flow

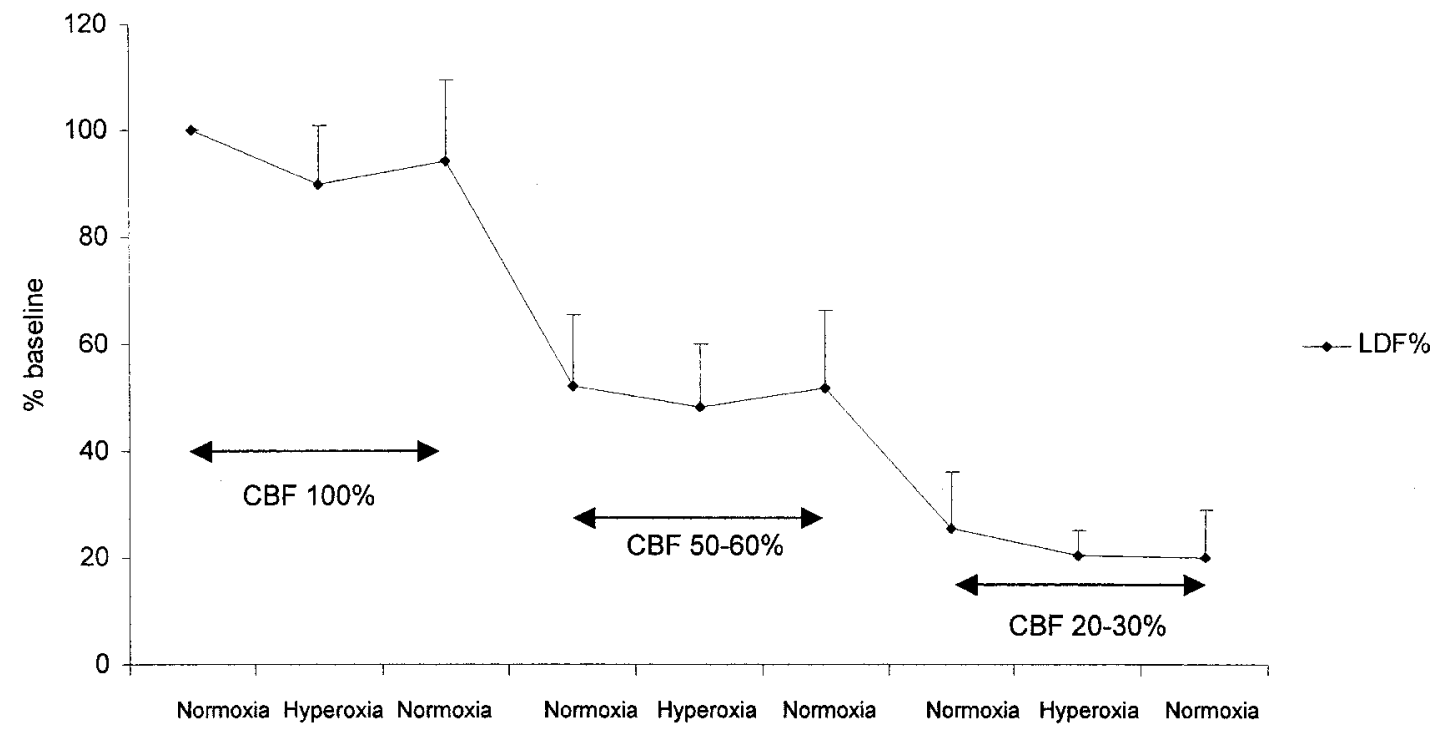

FIG. 7. CBF reductions during hyperoxia. 


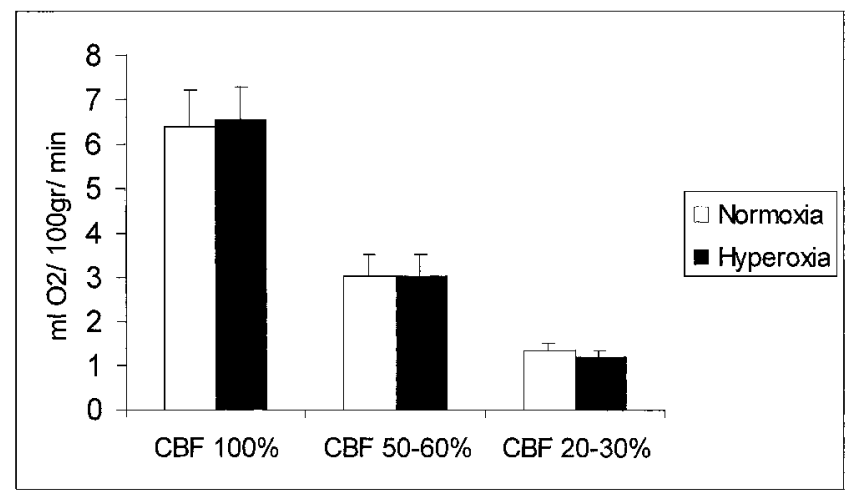

AVDO2

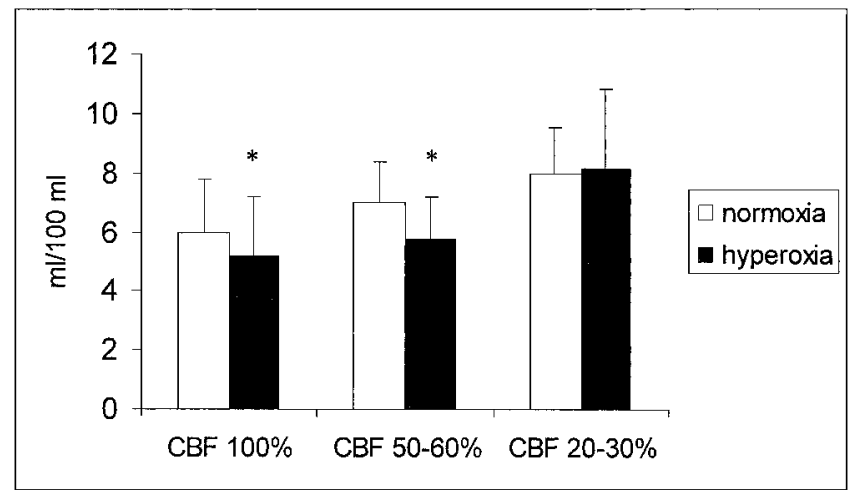

FIG. 8. Arteriovenous oxygen difference $\left(\mathrm{AVDO}_{2}\right)$ and brain oxygen delivery $\left(\mathrm{DO}_{2}\right)$ during normoxia and hyperoxia. $* p<0.05$ (paired $t$ test between $\mathrm{AVDO}_{2}$ in normoxia and in hyperoxia during the same CBF step).

(CBF in this case). The increase in the $\mathrm{O}_{2}$ dissolved fraction caused by arterial hyperoxia has a limited impact on $\mathrm{O}_{2}$ content, which is due mainly to the fraction bound to hemoglobin. Raising $\mathrm{paO}_{2}$ from 130 to $500 \mathrm{~mm} \mathrm{Hg}$ increases the $\mathrm{O}_{2}$ dissolved fraction by only $1.1 \mathrm{~mL} / \mathrm{dL}$ (to $0.003 * \mathrm{paO}_{2}$ ).

The second factor affecting $\mathrm{O}_{2}$ delivery is $\mathrm{CBF}$ which decreased (albeit only slightly) after arterial hyperoxia was induced in our experimental setting. This response has already been reported: arterial hyperoxia caused cerebral vasoconstriction, hence a decrease in CBF (Jacobson et al., 1963, 1964). It follows that $\mathrm{O}_{2}$ brain delivery cannot be increased substantially by manipulating the inspired oxygen fraction.

Therefore, we must distinguish between oxygen tension, which responds impressively to changes in inspired oxygen fraction, and oxygen content and delivery, which show a negligible change in response to hyperoxia, but are the key factors for sustaining aerobic metabolism.

It has been recently suggested that increasing $\mathrm{ptiO}_{2}$ by ventilation with pure oxygen may have a beneficial ef- fect on brain dysoxia (Menzel et al., 1999). The assumption is that simply increasing $\mathrm{ptiO}_{2}$ in the tissue might increase the driving force of $\mathrm{O}_{2}$ flux from the capillary to the mitochondria and might then cause a shift from anaerobic to aerobic metabolism.

Our $\mathrm{AVDO}_{2}$ data, however difficult to interpret, do not seem to confirm this. $\mathrm{AVDO}_{2}$ indicates the coupling, or the lack of coupling, between $\mathrm{CBF}$ and $\mathrm{O}_{2}$ metabolism $\left(\mathrm{CMRO}_{2}\right)$ and clearly illustrated the match/mismatch between $\mathrm{O}_{2}$ supply and demand during the three phases of intact, moderately and severely impaired CBF. However, at least in the first two phases, $\mathrm{AVDO}_{2}$ decreased after hyperoxia was induced. The relationship among $\mathrm{CBF}, \mathrm{CMRO}_{2}$ and $\mathrm{AVDO}_{2}$ can be expressed as $\mathrm{AVDO}_{2}=\mathrm{CMRO} / \mathrm{CBF}$. It follows that if $\mathrm{AVDO}_{2}$ decreases, this may be due to an increase in CBF or a decrease in $\mathrm{CMRO}_{2}$. In our conditions, $\mathrm{CBF}$ fell slightly during hyperoxia, so a decrease in $\mathrm{CMRO}_{2}$ may explain the $\mathrm{AVDO}_{2}$ data. This makes it difficult to find an agreement between the drop in $\mathrm{AVDO}_{2}$ and the theoretical restoration of oxidative phosphorylation 
induced by the elevation of $\mathrm{ptiO}_{2}$ in response to arterial hyperoxia, which would have led to an increase of $\mathrm{CMRO}_{2}$.

On the other hand, as CBF declined in line with the institution of hyperoxia, a reduction of $\mathrm{CMRO}_{2}$ can only be inferred to explain the reduction of $\mathrm{AVDO}_{2}$. Impaired glucose uptake and oxidation, probably due to interference with the pyruvate oxidase system, was found during ventilation with oxygen at 1 and 2 atmospheres (Jacobson et al., 1964). However, we believe that this needs further investigation using more direct methods to study cerebral metabolism.

Besides the results need to be repeated in animals who have undergone traumatic brain injury, since the cerebral metabolic derangements occurring after head trauma, may affect the response to arterial hyperoxia.

In conclusion, $\mathrm{ptiO}_{2}$ reductions closely reflect the imbalance between oxygen delivery and demand; this implies a link between low $\mathrm{ptiO}_{2}$ and defective $\mathrm{O}_{2}$ supply due to impaired CBF. However, this relation is not necessarily reciprocal, since manipulating brain oxygen tension does not always influence brain oxygen delivery, as in the case of ventilation with pure oxygen. Though the effects of arterial hyperoxia on brain metabolism need more study, we believe that for the time being at least the $\mathrm{ptiO}_{2}$ response to hyperoxia may be useful for investigating $\mathrm{O}_{2}$ diffusion impairment with respect to the spatial distribution of the brain microvasculature, but not for restoring oxidative metabolism.

\section{REFERENCES}

BERGSNEIDER, M., HOVDA, D.A., SHALMON, E., et al. (1997). Cerebral hyperglycolysis following severe traumatic brain injury in humans: a positron emission tomography study. J. Neurosurg. 86, 241-251.

BOUMA, G.J., MUIZELAAR, J.P., CHOI, S.C., et al. (1991). Cerebral circulation and metabolism after severe traumatic brain injury: the elusive role of ischemia. J. Neurosurg. 75, 685-693.

CORMIO, M., VALADKA, A.B., and ROBERTSON, C.S. (1999). Elevated jugular venous oxygen saturation after severe head injury. J. Neurosurg. 90, 9-15.

DINGS, J., MEIXENBERGER, J., and ROOSEN, K. (1997). Brain tissue $\mathrm{pO}_{2}$-monitoring: catheter stability and complications. Neurosurg. Int. Care 19, 241-245.

DINGS, J., MEIXENBERGER, J., JAGER, A., et al. (1998). Clinical experience with 118 brain tissue oxygen partial pressure catheter probes. Neurosurgery 43, 1082-1095.

DOPPENBERG, E.M.R., ZAUNER, A., WATSON, J.C., et al. (1998). Determination of the ischemic threshold for brain oxygen tension. Acta Neurochir. (Suppl.) 71, 166-169.
GIBBS, E.L., LENNOX, W.G., NIMS, L.F., et al. (1942). Arterial and cerebral venous blood. Arterial-venous differences in man. J. Biol. Chem. 144, 325-332.

GO, K.G. (1991). The cerebral blood supply, in: Cerebral Pathophysiology. K.G. Go (ed), Elsevier: Amsterdam, pps. 208-277.

GOPINATH, S.P., ROBERTSON, C.S., CONTANT, C.F., et al. (1994). Jugular venous desaturation and outcome after head injury. J. Neurol. Neurosurg. Psychiatry 57, 717-723.

GRAHAM, D.I., ADAMS, J.H., and DOYLE, D. (1978). Ischaemic brain damage in fatal non-missile head injury. J. Neurol. Sci. 39, 213-234.

JACOBSON, I., HARPER, A.M., and McDOWALL, D.G. (1963). The effects of oxygen under pressure on cerebral blood-flow and cerebral venous oxygen tension. Lancet $\mathbf{2}$, 549 .

JACOBSON, I., HARPER, A.M., and McDOWALL, D.G. (1964). The effects of oxygen at 1 and 2 atmospheres on the blood flow and oxygen uptake of the cerebral cortex. Surg. Gynecol. Obstet. 119, 737-742.

KIENING, K.L., UNTERBERG, A.W., BARDT, T.F., et al. (1996). Monitoring of cerebral oxygenation in patients with severe head injuries: brain tissue $\mathrm{Po}_{2}$ versus jugular vein oxygen saturation. J. Neurosurg. 85, 751-757.

KIENING, K., HARTL, R., UNTERBERG, A., et al. (1997). Brain tissue $\mathrm{pO}_{2}$ monitoring in comatose patients: implications for therapy. Neurol. Res. 19, 233-240.

LEACH, R.M., and TREACHER, D.F. (1998). ABC of oxygen. Oxygen transport-2. Tissue hypoxia. B.M.J. 317, 1370-1373.

LONGHI, L., FRANZINI, S., ROSSI, S., et al. (1999). Effects of hyperoxia on brain tissue oxygen tension in cerebral focal lesions. Presented at the 14th International Symposium on Critical Care Medicine, Trieste, Italy.

LUBBERS, D.W. (1977). Quantitative measurement and description of oxygen supply to the tissue, in: Oxygen and Physiological Function. Jobsis F.F. (ed), Professional Information Library: Dallas, pps. 254-276.

MAAS, A.I.R., FLECKENSTEIN, W., DEJONG, D.A., et al. (1993). Monitoring cerebral oxygenation: experimental studies and preliminary clinical results of continuous monitoring of cerebrospinal fluid and brain tissue oxygen tension. Acta Neurochir. (Suppl.) 59, 50-57.

MENZEL, M., DOPPENBERG, E.M.R., ZAUNER, A., et al. (1999). Increased inspired oxygen concentration as a factor in improved brain tissue oxygenation and tissue lactate levels after severe human head injury. J. Neurosurg. 91, 1-10.

PINSKY, M.R. (1994). Beyond global oxygen supply-demand relations: in search of measures of dysoxia. Intensive Care Med. 20, 1-3. 
PITTMAN, R.N. (1999). In microcirculation and tissue oxygenation, in: Tissue Oxygenation in Acute Medicine. W.J. Sibbald, K. Messmer, and M.P. Fink (eds), Springer: New York, pps. 36-54.

ROBERTSON, C.S., NARAYAN, R.K., GOKASLAN, Z.L., et al. (1989). Cerebral arteriovenous oxygen difference as an estimate of cerebral blood flow in comatose patients. J. Neurosurg. 70, 222-230.

STOCCHETTI, N., CHIEREGATO, A., DE MARCHI, M., et al. (1998). High cerebral perfusion pressure improves low values of local brain tissue $\mathrm{O}_{2}$ tension in focal lesions. Acta Neurochir. (Suppl.) 71, 162-165.

TREACHER, D.F., and LEACH, R.M. (1998). ABC of oxygen. Oxygen transport-1. Basic principles. B.M.J. 317, 1302-1306.

VALADKA, A.B., GOPINATH, S.P., CONTANT, C.F., et al. (1998). Relationship of brain tissue $\mathrm{pO}_{2}$ to outcome after severe head injury. Crit. Care Med. 26, 1576-1581.

VAN SANTBRINK, H., MAAS, A.I.R., and AVEZAAT, C.J.J. (1996). Continuous monitoring of partial pressure of brain tissue oxygen in patients with severe head injury. Neurosurgery $\mathbf{3 8}, 21-31$.
WEIL, M.H., RACKOW, E.C., TREVINO, R., et al. (1986). Difference in acid-base state between venous and arterial blood during cardiopulmonary resuscitation. N. Engl. J. Med. 315, 153-156.

ZAUNER, A., DOPPENBERG, E.M.R., WOODWARD, J.J., et al. (1997). Continuous monitoring of cerebral substrate delivery and clearance: initial experience in 24 patients with severe acute brain injuries. Neurosurgery 41, 1082-1093.

ZHANG, H., and VINCENT, J.L. (1993). Arteriovenous difference in $\mathrm{pCO}_{2}$ and $\mathrm{pH}$ are good indicators of critical hypoperfusion. Am. Rev. Respir. Dis. 148, 867-871.

Address reprint requests to: Sandra Rossi, M.D. Neuro ICU

Department of Anesthesia and Intensive Care Padiglione Beretta Ovest Ospedale Maggiore Policlinico IRCCS

Via F. Sforza 35 20122 Milano, Italy

E-mail: sandrarossi@usa.net 